REACTION KINETICS MECHANISMS AND CATALYSIS (ISSN: 1878-5190) (eISSN: 18785204) 115(1): 201-216 (2015).

DOI: $10.1007 / \mathrm{s} 11144-014-0825-9$

\title{
Hydroconversion of acetic acid over indium- and phosphorus-modified nickel/laponite catalysts
}

\author{
Gy. Onyestyák* ${ }^{1}$, Sz. Harnos ${ }^{1}$, C. A. Badari ${ }^{1}$, Sz. Klébert ${ }^{1}$, A. Kaszonyi ${ }^{2}$, J. Valyon ${ }^{1}$
}

${ }^{1}$ Institute of Materials and Environmental Chemistry, Research Centre for Natural Sciences, Hungarian Academy of Sciences, Magyar tudósok körútja 2, Budapest, H-1117, Hungary

${ }^{2}$ Department of Organic Technology, Slovak University of Technology, Radlinského 9, Bratislava, SK-81237, Slovak Republic

$(*)$ corresponding author: onyestyak.gyorgy@ @tk.mta.hu

\begin{abstract}
Modified catalysts were prepared from laponite (LT)-supported Ni catalyst. The catalysts were characterized by specific surface area (SSA), pore size distribution (PSD), in situ X-ray diffractometry (XRD) and activity in the hydroconversion of acetic acid (AA) at 21 bar total pressure, $\mathrm{WHSV}_{\mathrm{AA}}=0.5-3.0 \mathrm{~h}^{-1}$, and $260-380{ }^{\circ} \mathrm{C}$ reaction temperature. The modification generated LT-supported $\mathrm{Ni}_{2} \mathrm{In}$ or $\mathrm{Ni}_{2} \mathrm{P}$ active phases. The $\mathrm{Ni}_{2} \mathrm{P}$ catalyst showed hydrodecarbonylation (HDC) activity. The $\mathrm{Ni}_{2} \mathrm{In} / \mathrm{LT}$ catalyst has a balanced hydrogenating activity, providing ethanol (EL) and $\mathrm{H}_{2} \mathrm{O}$ as main products. The EL formation was substantiated to proceed through acetaldehyde (AAD)/vinyl alcohol intermediates.
\end{abstract}

Keywords Acetic acid hydroconversion, Ethanol, $\mathrm{Ni} /$ Laponite, $\mathrm{Ni}_{2} \mathrm{In} /$ Laponite, $\mathrm{Ni}_{2} \mathrm{P} /$ Laponite

\section{Introduction}

Processing of lignocellulosic biomass, composed mainly of carbohydrate polymers, to obtain higher value organic commodities or petrochemicals must involve multiple subsequent operations. As a first step, the polymeric chain must be destructed applying mechanical and biological, chemical or thermal treatments. Favorably, these procedures provide a liquid, often referred to as bio-oil. Value-added chemicals can be gained by fractionating the product mixture of previous treatment and subjecting fractions to further conversion steps, if needed. Obtaining fuel, being of higher energy density than the bio-oil, requires further reduction of the heteroatom content. Both pyrolytic and fermentative lignocellulose decompositions give fluids, comprising lower carboxylic acids as main components. The full hydrodeoxygenation (HDO) of $\mathrm{C}_{2}-\mathrm{C}_{4}$ carboxylic acids gives gaseous hydrocarbons, which are of low value compared to lower alcohols, which are liquid at ambient conditions. The partial reduction gives not only valuable alcohol as product but, as a further advantage, consumes less of costly hydrogen and generates less of worthless wastewater. The selective partial reduction needs catalyst that is active in the reduction of the carbonyl group to methylene group but shows low activity in alcohol dehydration and hydrogenolysis of bonds, because latter reactions would result in lower value gaseous products. The most common carboxylic acid gained by lignocellulose 
decomposition, is acetic acid (AA). Therefore, for studying the heterogeneous catalytic hydroconversion of carboxylic acids AA was selected as model reactant.

Oils of fossil origin contain organosulfur compounds as main undesirable impurity. The petrochemical industry applies mostly sulfide catalysts, such as sulfided $\mathrm{Ni}, \mathrm{Mo} / \gamma$-alumina, for oil hydrofining, involving hydrodesufurization (HDS) and hydrodenitrogenation (HDN) and hydrodeoxygenation (HDO) reactions. However, the sulfide catalysts are unfavorable for processing bio-oils, which contain mainly oxygen and are virtually free of sulfur. Noble metal and nickel catalysts are known to have high hydrogenation activity. However, this property is paralleled by undesired hydrodecarbonylation (HDC), hydrogenolysis and cracking activity [1-7]. Recent studies showed that modification of supported $\mathrm{Ni}$-catalysts by indium or phosphorus generates $\mathrm{Ni}_{2} \mathrm{In}$ or $\mathrm{Ni}_{2} \mathrm{P}$ phase, respectively [8-9]. The $\mathrm{Ni}_{2} \mathrm{P}$ catalyst is active in the HDS and the HDN reactions [9], whereas the $\mathrm{Ni}_{2} \mathrm{In}$ catalyst has enhanced activity and selectivity in the hydrogenation of carboxylic acids to alcohols and water $[2,8,10,11]$.

Rachmady et al. [1] studied AA hydrogenation over a series of supported platinum catalysts using $\mathrm{TiO}_{2}, \mathrm{SiO}_{2}$, $\mathrm{Al}_{2} \mathrm{O}_{3}$ and $\mathrm{Fe}_{2} \mathrm{O}_{3}$ supports and Pt powder catalyst without support. The titania-supported catalysts were found to be the most active and the most selective for ethanol formation. Over the Pt powder, $\mathrm{Pt} / \mathrm{SiO}_{2}$ and $\mathrm{Pt} / \eta-\mathrm{Al}_{2} \mathrm{O}_{3}$ the $\mathrm{HDC}$ and decomposition of AA prevailed. Recently we observed high activity of silica and alumina-supported Ni catalysts in the hydroconversion of carboxylic acids and the effect of indium doping on the activity of these catalyst preparations. We have found that $\mathrm{Ni} / \gamma-\mathrm{Al}_{2} \mathrm{O}_{3}[2,11]$ catalyst shows activity, similar to that of $\mathrm{Pt} / \eta-\mathrm{Al}_{2} \mathrm{O}_{3}$. $\mathrm{Mentioned}$ results clearly demonstrate the importance of gathering more knowledge about support effects in the HDO catalysis.

In the direct hydroconversion of carboxylic acids, supported $\mathrm{Ni}_{2} \mathrm{P}$ catalysts were not examined yet. In recent studies [12-13] $\mathrm{Ni}_{2} \mathrm{P}$, supported on porous silica, was applied for the HDO of methyl laurate. The lauric acid, obtained by hydrogenolysis or hydrolysis of the ester, is an intermediate of reactions, giving partially or fully deoxygenated $\mathrm{C}_{11}$ and $\mathrm{C}_{12}$ products. The size of the $\mathrm{Ni}_{2} \mathrm{P}$ crystallites and the turnover frequency (TOF) was shown to be strongly affected by the structure of the applied silica support. Weak interaction between the support and the active phase was proposed to promote generation of larger $\mathrm{Ni}_{2} \mathrm{P}$ crystallites (in the size range of 3-12 nm), wherein the electron density is higher on the active surface $\mathrm{Ni}$ atoms. The higher electron density on the Ni sites facilitates the dissociation of the C-O bond [14]. Obviously, the catalytic selectivity evolves in synergy of the active phase and the support.

Clay minerals are of commercial importance as catalyst supports, not only because of their great abundance and low cost but also due to their favorable structures and properties. By intercalating the parallel silicate layers of smectite clays, such as montmorillonite or hectorite, with particles of metal oxides or metals, high specific surface area can be generated, moreover, the surface properties and the pore structure can be tailored. Therefore, smectite clays are considered as a desirable starting material to fabricate catalysts [15]. In the present study laponite (LT), a widely used synthetic clay, isostructural with the natural hectorite, was applied as carrier of the active phases. The chemical formula of its unit cell was $\mathrm{Na}_{0.7}{ }^{+}\left[\mathrm{Li}_{0.3} \mathrm{Mg}_{5.5} \mathrm{Si}_{8} \mathrm{O}_{20}(\mathrm{OH})_{4}\right]^{0.7-}$. In the structure, octahedral magnesium ions are sandwiched between two layers of tetrahedral silicon atoms. The partial substitution of the magnesium by lithium provides the layer negative surface charge compensated by hydrated sodium cations. The dimensions of nano-sized elemental platelets, disc-like particles are the following: diameter $30 \mathrm{~nm}$ and thickness $0.9 \mathrm{~nm}$. In the dry state or in organic solvents, the platelets are piled up into tactoids of around 2-3 layers held together by long-range attractive forces. However, in contrast to clays with a large aspect ratio that tend to aggregate in a face-to-face lamellar fashion, laponite has a tendency to form partially delaminated disordered aggregates through edge-to-face and edge-to-edge interactions. 
The house of cards structure of laponite shows high thermal and hydrothermal stability. The mesoporous system, allowing free transport of relatively bulky reactant and product molecules to and from the catalytically active sites, made laponite to a favorable support for the active mono- or bimetallic particles. Introduction of metals, such as Pd, $\mathrm{Ni}, \mathrm{Cu}$, etc., into laponite pillared by $\mathrm{Al}_{2} \mathrm{O}_{3}, \mathrm{ZnO}_{2}, \mathrm{SiO}_{2}, \mathrm{Fe}_{2} \mathrm{O}_{3}$. or $\mathrm{TiO}_{2}$ [16-19] was shown to generate materials having high catalytic activity in selective NO reduction reaction [16], photo-Fenton oxidation [17], or in the total oxidation of benzene [18]. Lestari et al. [19] reported about the use of mesoporous Ni/Zr-laponite for the catalytic deoxygenation of vegetable oils into liquid hydrocarbons. Latter study initiated the choice of laponite as support for the catalysts of the present study, concerning the partial HDO of AA to ethanol (EL). We show that undesired side reactions, proceeding over the LT supported nickel catalyst, can be suppressed both by introduction of phosphorus or indium promoter.

\section{Experimental}

\subsection{Preparation of catalysts}

The LT, used as catalyst support, was the Laponite RD product of the Rockwood Clay Additives GmbH. Catalyst precursors were prepared, as described below, and reduced in $\mathrm{H}_{2}$ at elevated temperature to get active catalysts.

XRD examinations were carried out to follow the transformation of the catalyst precursors. The results suggested that the catalysts reduced at $650{ }^{\circ} \mathrm{C}$ contain $\mathrm{Ni}, \mathrm{Ni}_{2} \mathrm{In}$ or $\mathrm{Ni}_{2} \mathrm{P}$ phase on the $\mathrm{LT}$ support. Therefore, the catalysts are designated by specifying the active phase, whereas the same designation with a suffix $(\mathrm{P})$ refers to their precursors, such as, Ni/LT and Ni/LT(P). A number in front of the catalyst designation gives the mass of the active phase in weight percent, such as, $9 \mathrm{Ni} / \mathrm{LT}$.

The precursor of the supported Ni catalyst was prepared by incipient wetness impregnation of the LT using an aqueous solution of ammonia and nickel acetate (Aldrich). The impregnated clay was dried and calcined at $550{ }^{\circ} \mathrm{C}$.

The precursor of the supported nickel-indium bimetallic catalyst, the $\mathrm{Ni}_{2} \mathrm{In} / \mathrm{LT}(\mathrm{P})$ sample, was prepared from the above mentioned $\mathrm{Ni} / \mathrm{LT}(\mathrm{P})$ preparation by adding to it indium(III)oxide in an amount to get the required $\mathrm{Ni}$ to In molar ratio and grinding the mixture in agate mortar. To obtain virtually $\mathrm{Ni}_{2} \mathrm{In}$ phase only, the preferable $\mathrm{Ni}$ to In ratio is 2 .

The conventional method was applied to prepare the $\mathrm{Ni}_{2} \mathrm{P} / \mathrm{LT}(\mathrm{P})$ sample. The procedure began with the impregnation of the solid support by calculated amounts of $\mathrm{Ni}\left(\mathrm{NO}_{3}\right)_{2} \cdot 6 \mathrm{H}_{2} \mathrm{O}$ and $\left(\mathrm{NH}_{4}\right)_{2} \mathrm{HPO}_{4}$. Our preparation contained $1.16 \mathrm{mmol} \mathrm{Ni}\left(\mathrm{NO}_{3}\right)_{2} 6 \mathrm{H}_{2} \mathrm{O}$ and $2.30 \mathrm{mmol}\left(\mathrm{NH}_{4}\right)_{2} \mathrm{HPO}_{4}$ on $1 \mathrm{~g}$ of LT. It was obtained by suspending $1 \mathrm{~g}$ of LT in $25 \mathrm{~cm}^{3}$ solution containing mentioned compounds in the given amounts and $20 \mu \mathrm{cc}$. $\mathrm{HNO}_{3}$. The $\mathrm{pH}$ of the suspension was 2. After adjusting the $\mathrm{pH}$ to about 7 using $\mathrm{NH}_{3}$ solution a green suspension was obtained. It was stirred at room temperature for $1 \mathrm{~h}$. Most of the aqueous phase was separated from the solid by decantation and then by drying, first at room temperature and then at $120^{\circ} \mathrm{C}$. Finally, the dry solid was air-calcined at $400{ }^{\circ} \mathrm{C}$ for $4 \mathrm{~h}$. The calcined sample was ground, pressed to pellets and the pellets were broken to particles. The $0.315-0.63 \mathrm{~mm}$ size particles were separated by sieving and used as catalyst precursor.

In order to get activated catalyst an ex situ treatment was given to the $\mathrm{Ni}_{2} \mathrm{P} / \mathrm{LT}(\mathrm{P})$ catalyst precursor followed by an in situ $\mathrm{H}_{2}$-reduction of the preparation in the catalytic reactor. From the $\mathrm{Ni} / \mathrm{LT}(\mathrm{P})$ and $\mathrm{Ni}_{2} \mathrm{In} / \mathrm{LT}(\mathrm{P})$ precursors activated catalysts were obtained without ex situ treatment applying in situ reduction in the catalytic reactor (vide infra). The in situ reduction was carried out in a hydrogen flow of $100 \mathrm{~cm}^{3} / \mathrm{min}$ at 21 bar and $450{ }^{\circ} \mathrm{C}$ for $1 \mathrm{~h}$. In order to get comparative results with a commercial catalyst, an Adkins catalyst, consisting of $72 \mathrm{wt}^{\%} \mathrm{CuCr}_{2} \mathrm{O}_{4}$ and 28 wt.\% $\mathrm{CuO}$, was tested under similar conditions than the rest of the catalyst preparations. The ex situ treatment 
involved heating the $\mathrm{Ni}_{2} \mathrm{P} / \mathrm{LT}(\mathrm{P})$ catalyst precursor at a rate of $2^{\circ} \mathrm{C} \min ^{-1}$ up to $550{ }^{\circ} \mathrm{C}$ in $\mathrm{H}_{2}$ flow of $100 \mathrm{~cm}^{3} \mathrm{~min}^{-1}$ and continuing the $\mathrm{H}_{2}$ treatment on this temperature for $3 \mathrm{~h}$. The above mentioned XRD results suggested that this treatment generated supported $\mathrm{Ni}_{2} \mathrm{P}$ phase. Then the sample was cooled to room temperature in He flow. In order to prevent the bulk of the $\mathrm{Ni}_{2} \mathrm{P}$ particles to became oxidized when exposed to air the preparation was contacted with a $100 \mathrm{~cm}^{3} \mathrm{~min}^{-1}$ flow of $1.0 \% \mathrm{O}_{2} / \mathrm{N}_{2}$ gas at room temperature for $3 \mathrm{~h}$. Latter treatment stabilized the solid creating a phosphate-like surface layer over the pyrophoric $\mathrm{Ni}_{2} \mathrm{P}$ particles.

\subsection{Characterization}

Elemental analysis was carried out with Spectro Genesis type inductively coupled sequential plasma optical emission spectrometry (ICP-OES) applying radial plasma viewing. The catalysts had been dissolved in nitrous acid in a microwave digester. The nickel, indium and phosphorus signals were calibrated with a solution of nickel nitrate, indium(III)nitrate and ammonium phosphate. The metal content of the catalysts corresponded to the amount of metal impregnated on the support. The $\mathrm{Ni}_{2} \mathrm{In} / \mathrm{LT}$ catalysts contained $9 \mathrm{wt} \% \mathrm{Ni}$ and $8.3 \mathrm{wt} \%$ In. The Ni content of the $\mathrm{Ni}_{2} \mathrm{P} / \mathrm{LT}$ catalyst was 6 wt. \%, whereas the P content was 4 wt \% . Because $\left(\mathrm{NH}_{4}\right)_{2} \mathrm{HPO}_{4}$ was applied in large excess the $\mathrm{P}$ content of the catalyst was much higher than that, which would correspond to the $\mathrm{Ni}_{2} \mathrm{P}$ stoichiometry, but lower than the impregnated amount, because some $\mathrm{P}$ was released during the $\mathrm{H}_{2}$-treatment of the precursor in the form of phosphine.

XRD measurements were carried out in hot stage applying a high-temperature type HTK-1200 Anton-Paar chamber. The sample was heated up according to a set temperature program in situ in the chamber, flushed by a $60 \mathrm{~cm}^{3} / \mathrm{min} \mathrm{H}_{2}$ flow. XRD patterns were recorded at elevated temperatures and finally at room temperature by a Philips PW 1810/3710 type diffractometer running under XPert High Score computer program, applying monochromatized $\mathrm{CuK}_{\alpha}(\lambda=0.15418 \mathrm{~nm})$ radiation $(40 \mathrm{kV}, 35 \mathrm{~mA})$, and a proportional counter. Patterns were recorded between 15 and $65^{\circ} 2 \theta$ values. The step size and counting time were $0.02^{\circ}$ and 1 sec, respectively. The crystalline phases were identified using ICDD database. The average crystallite size was determined by the Scherrer equation evaluating the FWMH values with full profile fitting method.

The metal dispersion in the catalysts was examined by transmission electron microscopy carried out the morphological analysis of the samples with a FEI Morgagni 268D type TEM.

Isotherms of nitrogen adsorption at $-196^{\circ} \mathrm{C}$ were determined using Quantochrome Autosorb $1 \mathrm{C}$ instrument to derive SSA of the catalysts by the BET method. Samples for BET and TEM characterization were obtained after HTXRD studies (using the $\mathrm{Ni} / \mathrm{LT}(\mathrm{P})$ and $\mathrm{Ni}_{2} \mathrm{In} / \mathrm{LT}(\mathrm{P})$ precursors). The samples reduced in hydrogen flow at different pressures (1 or 21 bar) were similar.

\subsection{Evaluation of catalytic activity and selectivity}

The catalytic hydrotreatment of AA was carried out at 21 bar total pressure applying a fixed bed, flow-through stainless steel tube reactor. The inner diameter of the reactor tube was $16 \mathrm{~mm}$. Next to a $120 \mathrm{~mm}$ long preheating section was the catalyst bed having the same length. The reaction conditions were varied than in a narrow range around these parameters. Any of the reaction parameters, such as temperature, space time and partial pressures could be varied, while all the other parameters remained the same. The reaction temperature and the WHSV were varied in the ranges of $260-380^{\circ} \mathrm{C}$ and $0.5-3 \mathrm{~h}^{-1}$, respectively. The $0.25-0.65 \mathrm{~mm}$ particle size fraction of the catalyst precursors was used in the catalytic tests. The catalyst precursor was filled in the tube reactor in an amount that the total weight of $\mathrm{Ni}$ and LT should be $1.2 \mathrm{~g}$. Before catalytic measurement each catalyst precursor and also the Adkins catalyst was pre-treated in $\mathrm{H}_{2}$ flow $\left(100 \mathrm{~cm}^{3} / \mathrm{min}\right)$ at 21 bar pressure, $450{ }^{\circ} \mathrm{C}$ for 1 hour. The WHSV of AA was 
calculated for this catalyst weight regardless of the weight of P or In component in the modified Ni catalysts. The standard rate of hydrogen flow was $71 \mathrm{~cm}^{3} / \mathrm{min}$, whereas the AA was fed in the preheating section in liquid form at a rate of $1.2 \mathrm{~g} / \mathrm{min}$. When the WHSV of AA was changed the feed rate of AA and $\mathrm{H}_{2}$ was changed proportionately to keep the partial pressures of the reactants constant. To study the effect of partial pressures of the reactants and the WHSV of AA we had to leave the standard reaction conditions. The $\mathrm{H}_{2}$ partial pressure was varied by admixing He to $\mathrm{H}_{2}$ flow while the rate of AA feed and the total rate of gas flow were maintained. To vary the partial pressure of AA the standard WHSV of AA was applied, and both the composition and the total flow rate of the $\mathrm{H}_{2} / \mathrm{He}$ mixture was varied in order to keep both the $\mathrm{H}_{2}$ partial pressure and the WHSV of AA at its standard value. The reactor effluent was cooled to room temperature and the liquid and gas phases were separated. Steady state was attained usually in about 2 hours after setting the reaction parameters. After reaching the steady state liquid samples were collected for half hour periods. The liquid was analyzed for the organic components by gas chromatograph (GC, Shimadzu 2010) equipped with flame ionization detector (FID) and a RESTEK Rt-U-BOND capillary column. A $30 \mathrm{~cm}^{3} / \mathrm{min} \mathrm{flow} \mathrm{of}$ nitrogen was applied as carrier gas. The column temperature was $160{ }^{\circ} \mathrm{C}$.

The gas was analyzed by an on-line GC (HP 5890) equipped with thermal conductivity detector (TCD) and Carboxen 1006 PLOT capillary column. Helium was used as carrier gas at a flow rate of $30 \mathrm{~cm}^{3} / \mathrm{min}$. The analysis was carried out applying programmed column temperature. The temperature was $35{ }^{\circ} \mathrm{C}$ for 8 min, then the column was heated up at a rate of $10{ }^{\circ} \mathrm{C} / \mathrm{min}$ to $225^{\circ} \mathrm{C}$ whereon it was held for additional $10 \mathrm{~min}$.

The activity measurement of a catalyst under varied reaction conditions took about 30-50 hours. In this period, the catalyst did not show activity loss. Returning to the reaction conditions applied at the beginning of the serial experiment only imperceptible deviations were observed in the conversion and selectivity from that obtained at the beginning. Consequently, catalyst structure/composition must have been preserved in the state, attained upon generation of the active form. Thus, activity dependencies on the reaction parameters could be fairly studied using a single catalyst bed under varying reaction conditions.

Conversion of acetic acid was determined from the carbon mass balance based on the amount and composition of compounds in the liquid and the gaseous product. The gas chromatograph was calibrated for each component of the effluent, except water. From the total mass flow, partial mass flows were calculated for the individual components. The deviation from the perfect carbon balance was usually less than $5 \%$. In general, the difference of the oxygen content of the reactor feed and the analyzed effluent was used to get the amount of formed water. In some experiments the water content was determined by the mentioned calculation and also measured by GC. The measured and the calculated water contents did not deviate more than $\pm 2 \mathrm{wt} \%$. Stacked area graphs were compiled to characterize the activity and selectivity of the catalysts as a function of reaction temperature or space time. In this representation, the vertical distance of two neighboring curves gives the molar yield of a product in percents.

\section{Results and Discussion-}

The XRD patterns in Fig. 1 show the formation of the catalytically active phases at elevated temperature in hydrogen. Metal oxide phases can be detected in the $\mathrm{Ni} / \mathrm{LT}(\mathrm{P})$ and $\mathrm{Ni}_{2} \mathrm{In} / \mathrm{LT}(\mathrm{P})$ catalyst precursors even after $\mathrm{H}_{2}$ treatment at $200{ }^{\circ} \mathrm{C}$ (Fig. 1, a1 and b1). The absence of any reflection on the XRD pattern of the Ni/LT(P) after $\mathrm{H}_{2}$ treatment at $450{ }^{\circ} \mathrm{C}$ shows the absence of long range order in any metal or metal oxide phase, whatever is present (Fig. 1, a2). When the reduction temperature was raised to $650{ }^{\circ} \mathrm{C}$, the XRD measurement detected Ni particles (Fig. 1, a3). The average size of the particles is about $10 \mathrm{~nm}$, calculated by the Scherrer equation. The Ni particles observable on the TEM image of the sample have also about this size (Fig 2A). In presence of both indium and nickel 
on the support, the $\mathrm{H}_{2}$ treatment at $650{ }^{\circ} \mathrm{C}$ generated intermetallic $\mathrm{Ni}_{2} \mathrm{In}$ phase (Fig. 1, b3). In corresponding experiment with supported indium oxide, strong reflections of In metal were obtained (not shown). The intensity of the $\mathrm{Ni}_{2} \mathrm{In}$ diffraction lines parallels the extent of reduction. Reduction at $450{ }^{\circ} \mathrm{C}$ decreased the intensity of the $\mathrm{In}_{2} \mathrm{O}_{3}$ reflections and gave rise to very weak reflections of $\mathrm{Ni}_{2} \mathrm{In}$ phase (Fig. 1, b2). Thus, the absence of lines from $\mathrm{In}_{2} \mathrm{O}_{3}$ and In metal may suggest that indium was quantitatively consumed in reaction with nickel. The average size of the $\mathrm{Ni}_{2}$ In particles was estimated from the broadening of the strongest XRD line, assuming that there is negligible broadening of reflection(s) due to the occurrence of disorder and lattice strain. This size obtained was $14 \mathrm{~nm}$ that is in accordance with that seen on the TEM micrograph (Fig. 2A).

The evolution of $\mathrm{Ni}_{2} \mathrm{P}$ phase on the surface of LT support is shown by the XRD results in Fig. 1, c1-c3. Interestingly, no crystalline phase could by identified in the $\mathrm{Ni}_{2} \mathrm{P} / \mathrm{LT}(\mathrm{P})$ sample and no crystalline phase was generated upon $\mathrm{H}_{2}$ treatment at $450{ }^{\circ} \mathrm{C}$ (Fig. 1, c1). Ordered $\mathrm{Ni}_{2} \mathrm{P}$ structure could be identified after continued treatment at $550^{\circ} \mathrm{C}$ (Fig. 1, c2). High reduction temperature and full reducibility for all precursors was confirmed with dynamic $\mathrm{H}_{2}$-TPR measurements (not shown). E.g. for $\mathrm{Ni}_{2} \mathrm{P} / \mathrm{LT}(\mathrm{P})$ the main peak was detected at $696{ }^{\circ} \mathrm{C}$ similarly to data shown in ref. 13. However, we take for more reliable step-by-step HT-XRD technique to follow up formation of active metallic phases leaving enough time to take place complete reduction at the investigated temperatures. The Scherrer analyses of the reflection suggested that the average size of the $\mathrm{Ni}_{2} \mathrm{P}$ particles, generated by hydrogen treatment at $650{ }^{\circ} \mathrm{C}$, was about $120 \mathrm{~nm}$ (Fig. 1, c2). This particle size is in harmony with that obtained by TEM measurement (Fig. 2B) and low, $0.13 \mathrm{Ni}$ dispersion value estimated from hydrogen chemisorption. The large $\mathrm{Ni}_{2} \mathrm{P}$ crystals show sharp square contours.

A number of TEM pictures were made. The size of the $\mathrm{Ni}_{2} \mathrm{P}$ particles was found to be roughly uniform, whereas the size distribution of the $\mathrm{Ni}$ and the $\mathrm{Ni}_{2} \mathrm{In}$ particles was much broader in a significantly lower size range (Fig. $2 \mathrm{~A}$, B). The significant size difference of $\mathrm{Ni}_{2} \mathrm{In}$ and $\mathrm{Ni}_{2} \mathrm{P}$ particles were obvious.

The large difference in the average particle size of the two kinds of active phases suggests that the $\mathrm{Ni}_{2} \mathrm{P}$ precursors have a weaker interaction with the LT surface those of the $\mathrm{Ni}_{2} \mathrm{In}$ phase. Strong support-precursor interaction facilitates the formation of smaller active particles. In smaller $\mathrm{Ni}_{2} \mathrm{P}$ particles the $\mathrm{Ni}-\mathrm{P}$ interaction is stronger than in larger $\mathrm{Ni}_{2} \mathrm{P}$ particles [15]. Strong Ni-P interaction reduces the electron density on the Ni atoms. According to the theoretical calculations high electron density of the metal site facilitates the dissociation of C-O bond and $\mathrm{H}_{2}$ [20]. Indeed, the specific activity of the sites was found higher in larger than in smaller particles [14].

The unique house of cards pore structure of laponite can also influence differently the size of $\mathrm{Ni}_{2} \mathrm{P}$ and $\mathrm{Ni}_{2} \mathrm{In}$ crystallites building up from extremely different modifying elements with different mechanism. The difference in the particle size involves large difference in the specific surface area of the active phases. However, the supported phases might have different accessibility for the reactants. Isotherms of nitrogen adsorption over the LT and the LTsupported catalysts are shown in Fig. 3A.

The shape of the isotherms is similar but the nitrogen uptake and the SSA of the catalysts is lower than those of the pure LT. The significant loss of LT surface area must happen due to partial blocking of the micropores due to deposition of active phase on the clay.

It must be noticed that the isotherms of the $\mathrm{Ni}_{2} \mathrm{In} / \mathrm{LT}$ and $\mathrm{Ni}_{2} \mathrm{P} / \mathrm{LT}$ catalysts approaches the saturation relative pressure above about $\mathrm{p} / \mathrm{p}_{0}=0.8$ differently than the isotherms of the $\mathrm{LT}$ and Ni/LT samples. The increasing nitrogen uptake in this pressure region suggests that a fraction of the mesopores must have been converted into much larger pores (Fig. 3B). This change did not alter the shape of the hysteresis loop, characteristic on adsorption-desorption of a 
material having slit-like pores between sheets. The narrow pressure range, where the smaller mesopores empty by capillary evaporation indicates, that a large fraction of the LT preserved its texture.

Nickel and indium can form seven intermetallic compounds, such as, $\mathrm{NiIn}, \mathrm{Ni}_{2} \mathrm{In}, \mathrm{Ni}_{3} \mathrm{In}_{2} \mathrm{Ni}_{4} \mathrm{In} \mathrm{Ni}_{2} \mathrm{In}_{3}$ and $\mathrm{Ni}_{10} \mathrm{In}_{27}$. (The crystalline phases were identified using the JSPDS ICDD database). It is not easy to tell which compositions are present on the LT support and which of them is active in the studied catalytic reaction. One of the difficulties comes from the absence of long-range order, making the phase not detectable by the XRD. The similar diffraction patterns of the different compounds, as far as the main diffraction lines are concerned, causes also complication. The XRD results, presented in Fig. 4, provide evidence that the $\mathrm{Ni}_{2} \mathrm{In}$ compound is the dominant active phase in our catalyst preparation.

The 9Ni/LT(P) sample was mixed with $10 \mathrm{wt} . \%$ indium(III)oxide to get a powder having a Ni to In ratio of 2. The solid was reduced in $\mathrm{H}_{2}$ for 30 min subsequent intervals at 450,550 , and $650{ }^{\circ} \mathrm{C}$. At the end of each interval an XRD pattern was recorded at room temperature. The amount of $\mathrm{Ni}_{2} \mathrm{In}$ phase generated from the $\mathrm{Ni}{ }_{2} \mathrm{In} / \mathrm{LT}(\mathrm{P}) \mathrm{depends}$ on the conditions of the reduction (Fig. 4). Obviously, a fraction of the indium(III)oxide was reduced to $\operatorname{In}^{0}$ at $450{ }^{\circ} \mathrm{C}$. No lines of $\mathrm{Ni}^{0}$ appeared. New reflections, indicating the formation of intermetallic-compound could be hardly discerned (Fig. 4). At $550{ }^{\circ} \mathrm{C}$ temperature of reduction all the $\operatorname{In}_{2} \mathrm{O}_{3}$ phase disappeared, the only detectable phases were $\mathrm{In}^{0}$ and a new phase, assigned to a kind of Ni-In intermetallic phase. No lines of $\mathrm{Ni}^{0}$ appeared. According to Fig. 1 the nickel reduced at $650{ }^{\circ} \mathrm{C}$ can form XRD detectable $\mathrm{Ni}^{0}$ particles. However, no $\mathrm{Ni}^{0}$ reflections appeared, but stronger lines of the same intermetallic Ni-In phase, which were detected already after reduction at $550{ }^{\circ} \mathrm{C}$ (Fig. 4 ). The absence of $\mathrm{Ni}^{0}$ lines indicate that nickel metal particles, if formed, became alloyed by indium, before they could take up an ordered metallic form. Neither $\mathrm{In}^{0}$ nor $\mathrm{Ni}^{0}$ phase was detectable suggesting that the formed intermetallic phase has the $\mathrm{Ni} / \mathrm{In}=2$ stoichiometry of the starting $\mathrm{In}_{2} \mathrm{O}_{3}-\mathrm{Ni} / \mathrm{LT}(\mathrm{P})$ mixture, moreover, that Ni-In intermetallic phases having composition with $\mathrm{Ni} / \mathrm{In}>2$ could not be obtained in significant amount. The intermetallic phase gives XRD line at $2 \Theta=28.895^{\circ}$ and a characteristic doublet at about $2 \Theta=43.237^{\circ}$.

The formation of phases with stoichiometry $\mathrm{Ni} / \mathrm{In}<2$ was also ruled out by an in situ XRD experiment similar that above. An $\mathrm{In}_{2} \mathrm{O}_{3}-9 \mathrm{Ni} / \mathrm{LT}$ mixture, containing indium in surplus to the $\mathrm{Ni}_{2} \mathrm{In}$ stoichiometry was reduced at $650{ }^{\circ} \mathrm{C}$ (Fig. 4). The XRD lines of the $\mathrm{Ni}_{2} \mathrm{In}$ phase appear with the same intensity than in the previous experiment, and the surplus indium gives reflections of $\mathrm{In}^{0}$. These results suggest that phases of $\mathrm{Ni} / \mathrm{In}<2$ were not formed. These results inform us about the bulk composition of the active phase, but do not infer that the active surface has the same stoichiometry.

The Ni/LT catalyst shows high hydroconversion activity (Figure 5A). The AA conversion increased near to linearly with increasing reaction temperature however the main product was low value methane. Some alcohol was also formed, which could react with the AA to give ethyl acetate (EA). This is common behavior of most supported nickel and precious metal catalysts $[1,2,8,21]$. Methane can be obtained by decarboxylation $\left(\mathrm{CH}_{3} \mathrm{COOH}_{\rightarrow} \mathrm{CH}_{4}+\right.$ $\left.\mathrm{CO}_{2}\right)$ or $\mathrm{HDC}\left(\mathrm{CH}_{3} \mathrm{COOH}+\mathrm{H}_{2} \rightarrow \mathrm{CH}_{4}+\mathrm{CO}+\mathrm{H}_{2} \mathrm{O}\right)$ of AA. However, neither $\mathrm{CO}_{2}$ nor $\mathrm{CO}$ is among the products. They must have been formed as intermediates, which were readily reduced to methane over the active $\mathrm{Ni} / \mathrm{LT}$ hydrogenation catalyst.

The AA hydroconversion, increases much more rapidly with the temperature over the $\mathrm{Ni}_{2} \mathrm{In} / \mathrm{LT}$ than over the Ni/LT catalyst (cf. Fig. 5A and 5B). The reaction of $\mathrm{AA}$ and $\mathrm{H}_{2}$ was substantiated to proceed by LangmuirHinschelwood mechanism (vide infra). Thus, rate of the bimolecular reaction depends on the coverage of the reactants and the rate constant of the reaction. At fixed reactant composition and space time the conversion is related to the rate of the reaction. Both the rate constant and the surface concentrations of the reactants depend on the 
reaction temperature. At about $280{ }^{\circ} \mathrm{C}$ the $\mathrm{Ni} / \mathrm{LT}$ is slightly more active than the $\mathrm{Ni} \mathrm{I}_{2} \mathrm{In} / \mathrm{LT}$. However, a $20{ }^{\circ} \mathrm{C}$ increase in the reaction temperature causes stronger increase in the conversion over the $\mathrm{Ni}_{2} \mathrm{In} / \mathrm{LT}$ than over the $\mathrm{Ni} / \mathrm{LT}$. The change in the relative coverage of the reactants may contribute to the activity increase, however, the much faster increase of the conversion over the $\mathrm{Ni}_{2} \mathrm{In} / \mathrm{LT}$ than over $\mathrm{Ni} / \mathrm{LT}$ catalyst substantiate that the rate constant of the reaction over the $\mathrm{Ni}_{2} \mathrm{In} / \mathrm{LT}$ increases more significantly than that over the $\mathrm{Ni} / \mathrm{LT}$. In other words, the activation energy of the reaction is most probably higher over the $\mathrm{Ni}_{2} \mathrm{In} / \mathrm{LT}$ than over the $\mathrm{Ni} / \mathrm{LT}$. At $330{ }^{\circ} \mathrm{C}$ almost full conversion was obtained. The main products were ethanol and water. No methane was formed. Small amount of acetaldehyde (AAD) and much less EA were also obtained. The $\mathrm{AAD}$ is intermediate of alcohol formation. $\mathrm{The}_{\mathrm{Ni}} \mathrm{In} / \mathrm{LT}$ catalyst, having a balanced activity to hydrogenate $\mathrm{C}-\mathrm{O}$ and $\mathrm{C}=\mathrm{C}$ bonds is a contact for selective EL formation from $\mathrm{AA}$ (Eq. 1).

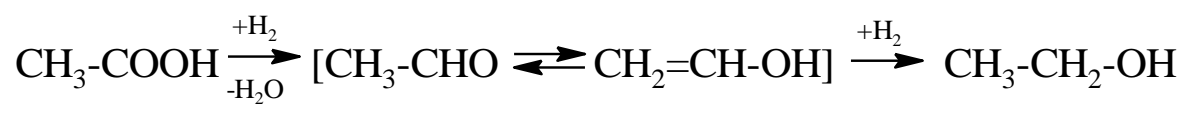

The main reaction route is the reduction of AA through AAD intermediate to EL. As in a consecutive reaction the concentration of the intermediate depends on the rate constants of the consecutive steps and on the space time. The main reaction route has side routes wherein the AA, EL participate in side reaction giving EA. The EA formation can proceed in a direct esterification reaction between the unconverted AA and the product EL. An alternative route of EA formation is the addition of AA to ethylene that could have been formed by EL dehydration. In absence of ethylene or ethane as product, we can conclude that EL is either not dehydrated under the conditions of the reaction or its consumption in the EA forming addition reaction is very rapid. It is difficult to see clear because $\mathrm{C}$-O bond hydrogenolysis of the formed EA also can give AAD and EL.

For comparison, the product distribution of AA hydroconversion over a commercial, old-fashioned Adkins catalyst is shown in Fig. 5D. Neither the $\mathrm{Ni}_{2} \mathrm{In} / \mathrm{LT}$ nor the Adkins catalysts generated methane. However, a larger fraction of the AA suffered partial deoxygenation over the $\mathrm{Ni}_{2} \mathrm{In} / \mathrm{LT}$ than over the Adkins catalyst under comparable reaction conditions. The laponite supported $\mathrm{Ni}_{2}$ In catalyst showed similar activity than the corresponding alumina supported catalyst (shown in Ref. 11). However, the unique clay structure has the potential of obtaining better catalyst simply by modifying the clay.

In Fig. 6 the yields of products are shown as function of space time. The yields of AAD and EA passed through maximum indicating that these products were intermediates of a consecutive hydroconversion process. The AAD zone is the widest at about space time $0.5 \mathrm{~h} \times \mathrm{g}_{\text {cat }} / \mathrm{g}_{\mathrm{AA}}$. The maximum is less obvious for EA. EA is also intermediate of EL formation, but to get higher EA conversion longer space time or temperature is needed. Consequently, EL can be produced selectively over $\mathrm{Ni}_{2} \mathrm{In} / \mathrm{LT}$ catalyst just by selecting right reaction conditions. All possible routes in the reaction network are summarized in Scheme 1 where highlighted pathways are shown typifying the three different catalysts.

The $\mathrm{Ni}_{2} \mathrm{P} / \mathrm{LT}$ catalyst was less active and selective for EL than either the $\mathrm{Ni} / \mathrm{LT}$ or the $\mathrm{Ni}_{2} \mathrm{In} / \mathrm{LT}$. The lower activity can be related partly with the relatively large crystallite size and low surface area of the active phase. The $\mathrm{Ni}_{2} \mathrm{P} / \mathrm{LT}$ catalyst also shows dominant HDC activity (similarly to $\mathrm{Ni}_{2} \mathrm{P}$ catalysts formed on various supports [12, 14]) but lower hydrogenation activity than the $\mathrm{Ni} / \mathrm{LT}$ as indicated by the appearance of $\mathrm{CO}$ and methane in the product mixture in near to molar equivalence (cf. Fig. 5, A and C). The product distribution remained the same in a wide temperature range. The yield of EL and AAD was minor. The low yield of EL is explained by the relatively high yield of EA. Interestingly very low yields of AAD were obtained both over $\mathrm{Ni} / \mathrm{LT}$ and $\mathrm{Ni}_{2} \mathrm{P} / \mathrm{LT}$ catalysts, showing HDC activity. In an earlier study [22], HDO of aliphatic carboxylic acids was substantiated to proceed over supported 
oxide and metal catalysts by Langmuir-Hinshelwood mechanism. Supported metal catalysts were suggested to activate hydrogen for attacking the $\mathrm{C}-\mathrm{C}$ bond between the carboxyl group and the alpha carbon atom of adsorbed carboxylic acid generating alkane and formic acid, which latter is readily decomposed to $\mathrm{CO}$ and $\mathrm{H}_{2} \mathrm{O}$. This mechanism can explain the absence of AAD in the product mixture. Alternatively, AAD might be an intermediate, consumed not only by EL-forming $\mathrm{H}_{2}$-reduction but also by rapid decarbonylation $\left(\mathrm{CH}_{3} \mathrm{CHO} \rightarrow \mathrm{CO}+\mathrm{CH}_{4}\right)$ by a mechanism similar to that mentioned above.

The dependence of activity on the partial pressure of the reactants suggested that Langmuir-Hinshelwood mechanism controls the bimolecular reaction between the acid and $\mathrm{H}_{2}$ over the catalysts of present study (Fig. 7). In principle, the highest reaction rate is obtained if the active sites are evenly covered by activated AA and $\mathrm{H}_{2}$. Actually, the strongly adsorbing AA covered most of the active sites already at moderate partial pressure. The conversion increased, if the hydrogen coverage was increased by elevating the $\mathrm{H}_{2}$ partial pressure in all the available pressure range, indicating that the $\mathrm{H}_{2}$ coverage never reached or exceeded that of AA (Fig. 7A). In contrast, at the available highest $\mathrm{H}_{2}$ partial pressure the reaction rate could be increased to a maximum by decreasing the AA partial pressure. If the AA partial pressure was further decreased, the AA coverage became the rate limiting factor (Fig. 7B).

The indium-promoted supported nickel catalyst has been found to be very selective in the reduction of AA with hydrogen to EL. The selectivity is attributed to $\mathrm{Ni}_{2} \mathrm{In}$ intermetallic compound obtained from the oxides of the metals by the simultaneous $\mathrm{H}_{2}$ reduction. The bimetallic $\mathrm{Ni}_{2} \mathrm{In}$ catalyst can be an environmental benign alternative of the chromium-containing Adkins catalyst and cheaper substitute of the expensive precious metal catalysts in the selective reduction of carboxylic acids. The indium modification steered the AA hydroconversion reaction on another route.

\section{Conclusions}

Laponite (LT) with unique house of cards pore structure is a catalyst support of high surface area. The large difference in the average particle size of the two kinds of active phases suggests that the $\mathrm{Ni}_{2} \mathrm{P}$ precursors have a weaker interaction with the LT surface those of the $\mathrm{Ni}_{2} \mathrm{In}$ phase. As a consequence an order of magnitude larger supported $\mathrm{Ni}_{2} \mathrm{P}$ particles were obtained than $\mathrm{Ni}_{2}$ In particles. Well-shaped, large $\mathrm{Ni}_{2} \mathrm{P}$ cubes were formed. Based on the temperature of $50 \%$ conversion the catalysts show an order of acetic acid hydroconversion activity $\mathrm{Ni}_{2} \mathrm{In} / \mathrm{LT}>\mathrm{Ni} / \mathrm{LT}>$ $\mathrm{Ni}_{2} \mathrm{P} / \mathrm{LT}$. The catalytic hydroconversion attacks the $\mathrm{C}-\mathrm{C}, \mathrm{C}-\mathrm{O}$ and a $\mathrm{C}=\mathrm{O}$ bonds of acetic acid. The hydrogenolysis of the $\mathrm{C}-\mathrm{O}$ bond, providing acetaldehyde (AAD) and water proceeds over all the Ni-containing catalysts of the present study. The hydrodecarbonylation reaction requires attack of the $\mathrm{C}-\mathrm{C}$ bond of the acetic acid or acetaldehyde, providing $\mathrm{HCOOH}$ or $\mathrm{HCOH}$ transient states, respectively, which relax releasing $\mathrm{CO}$. Over the $\mathrm{Ni}_{2} \mathrm{P} / \mathrm{LT}_{\text {catalyst, the }}$ hydroconversion stops at the hydrodecarbonylation stage, whereas over the Ni/LT catalyst all carbon is reduced to methane. Over $\mathrm{Ni}_{2} \mathrm{In} / \mathrm{LT}$ the hydrogen cannot cut the $\mathrm{C}-\mathrm{C}$ bond but can saturate the $\mathrm{C}=\mathrm{C}$ bond of vinyl alcohol, the tautomer of AAD, to generate ethanol. The yield of the liquid organic products obtained by partial deoxygenation of AA is the highest over the $\mathrm{Ni}_{2} \mathrm{In} / \mathrm{LT}$ catalyst.

\section{Acknowledgement}

Thanks is due to the Hungary-Slovakia Cross-border Co-operation Programme (Project registration number: HUSK/1101/1.2.1/0318) for supporting this research. The author wishes to express his appreciation to Mrs. Ágnes Farkas Wellisch for her excellent technical assistance. Thanks to the European Union and the State of Hungary cofinanced by the European Social Fund in the framework of TÁMOP 4.2.4. A/2-11-1-2012-0001 'National Excellence Program' for the further support. 


\section{References}

1 Rachmady W, Vannice MA (2000) J Catal 192:322-334

2 Onyestyák Gy, Harnos Sz, Kalló D (2011) Catal Comm 16:184-188

3 Wan H, Chaudary RV, Subramaniam B (2013) Energy \& Fuels 27:487-493

4 Olcay H, Xu L, Xu Y, Huber GW, (2010) Chem Cat Chem 2:1420-1424

5 Takeda Y, Nakagawa Y, Tomishige K (2012) Catal Sci Technol 2:2221-2223

6 Manyar HG, Paun C, Pilus R, Rooney DW, Thompson JM, Hardcare C, (2010) Chem Comm 46:6279-6281.

7 Alcala R, Shabaker JW, Huber GW, Sanchez-Castillo MA, Dumesic JA (2005) J Phys Chem B 109:2074-2085

8 Onyestyák Gy, Harnos Sz, Kalló D (2013) in Woo HG, Choi HT (eds) Indium: Properties, Technological Applications and Health Issues, Nova Science Publishers, New York, pp. 53-79

9 Oyama ST, Lee Y-K, (2005) J Phys Chem B 109:2109-2119

10 Sawhill SJ, Phillips DC, Bussell ME (2003) J Catal 215:208-219

11 Onyestyák Gy, Harnos Sz, Kaszonyi A, Štolcová M, Kalló D, (2012) Catal Com 27:159-163

12 Yang Y, Chen J, Shi H. (2013) Energy \& Fuels 27:3400-3409

13 Chen J, Shi H, Li L, Li K (2014) Appl Catal B 144:870-884

14 Oyama ST, Lee Y-K, (2008) J Catal 258:393-400

15 De Stefanis A, Tomlinson AAG (2006) Catal Today 114:126-141

16 Long R, Yang RT, Zammit KD (2003) US Patent 6521559 B1

17 Sum OSN, Feng J, Hu X, Yue PL (2004) Chem Eng Sci 59:5269-5275

18 Jinjun L, Zheng J, Zhengping H, Xiuyan X, Yahui Z (2005) J Mol Catal A 225:173-179

19 Lestari S, Beltramini J, Lu GQ (2006) in Proc of Int Conf on Nanoscience and Nanotechnology, Brisbane, Australia, Vols 1 and 2, pp. 159-162.

20 Whiffen VML, Smith KJ (2010) Energy Fuels 24:4728-4737

21 Onyestyák Gy (2013) Catal Comm 38:50-53

22 Boda L, Onyestyák Gy, Solt H, Lónyi F, Valyon J, Thernesz A (2010) Appl Catal A 374:158-169

\section{Figure captions}

Fig. 1 The evolution of active metal phases. In situ X-ray diffractograms of catalyst precursors and catalysts (a1-a3) 9Ni/LT, (b1-b3), 9Ni ${ }_{2} \mathrm{In} / \mathrm{LT}$, and (c1-c3) $10 \mathrm{Ni}_{2} \mathrm{P} / \mathrm{LT}$ were recorded using a high-temperature XRD cell. The samples were successively heated up to the indicated temperature and kept at that temperature for 30 min in a flow of atmospheric $\mathrm{H}_{2}$. The XRD patterns were recorded after each treatment at room temperature

Fig. 2 TEM micrographs of (A) $9 \mathrm{Ni} / \mathrm{LT}$, (B) $17 \mathrm{Ni}_{2} \mathrm{In} / \mathrm{LT}$, and (C) $10 \mathrm{Ni}_{2} \mathrm{P} / \mathrm{LT}$ catalysts. Catalysts were obtained from their precursors by reduction in $\mathrm{H}_{2}$ flow at $550{ }^{\circ} \mathrm{C}$ for $3 \mathrm{~h}$

Figure 3. (A) Adsorption isotherms of nitrogen at $-196{ }^{\circ} \mathrm{C}$ and (B) cumulative PSD for the pores having pore diameter larger than about $3.6 \mathrm{~nm}$. 
Fig. 4 The evolution of active metal phases. In situ X-ray diffractograms of mixtures $9 \mathrm{Ni} / \mathrm{LT}+10 \mathrm{wt} . \% \mathrm{In}_{2} \mathrm{O}_{3}$ and $9 \mathrm{Ni} / \mathrm{LT}+30$ wt. $\% \mathrm{In}_{2} \mathrm{O}_{3}$ were recorded using a high-temperature XRD cell. The samples were successively heated up to the indicated temperature and kept at that temperature for $30 \mathrm{~min}$ in a flow of atmospheric $\mathrm{H}_{2}$. The XRD patterns were recorded after each treatment at room temperature

Fig. 5 Stacked area graphs, showing the composition of the reactor effluent from AA hydroconversion over (A) $\mathrm{Ni} / \mathrm{LT}$, (B) $\mathrm{Ni}_{2} \mathrm{In} / \mathrm{LT}$, (C) $\mathrm{Ni}_{2} \mathrm{P} / \mathrm{LT}$ and (D) commercial Adkins catalyst (taken from Ref. 11) as a function of temperature at $\mathrm{WHSV}_{\mathrm{AA}}=1.0 \mathrm{~h}^{-1}$ and 21 bar total pressure. The distance between neighboring curves in percents gives the yield of the indicated product at any selected temperature. The percents above the uppermost curve up to $100 \%$ give the concentration of the unconverted AA in the reactor effluent.

Fig. 6 The hydroconversion of AA over $17 \mathrm{Ni}_{2} \mathrm{In} / \mathrm{LP}$ catalyst as a function of space time. The reaction was carried out at 21 bar total pressure and $320^{\circ} \mathrm{C}$

Fig. 7 Yields and selectivities of AA conversion over $17 \mathrm{Ni}_{2} \mathrm{In} / \mathrm{LP}$ catalyst at $\mathrm{WHSV}_{\mathrm{AA}}=1.0 \mathrm{~h}^{-1}, 21$ bar total pressure, and $300{ }^{\circ} \mathrm{C}$ as function of (A) $\mathrm{H}_{2}$ partial pressure, while the AA partial pressure was kept at 1.7 bar and as function of (B) AA partial pressure, while the $\mathrm{H}_{2}$ partial pressure was kept at 11 bar. Reactant partial pressures were adjusted by feeding $\mathrm{H}_{2}$, He and AA in required proportions 
Scheme 1. Schematic diagram of reactions involved in the conversion of acetic acid, based on the products formed over $\mathrm{Ni} / \mathrm{LT}, \mathrm{Ni}_{2} \mathrm{In} / \mathrm{LT}$ and $\mathrm{Ni}_{2} \mathrm{P} / \mathrm{LT}$ catalysts

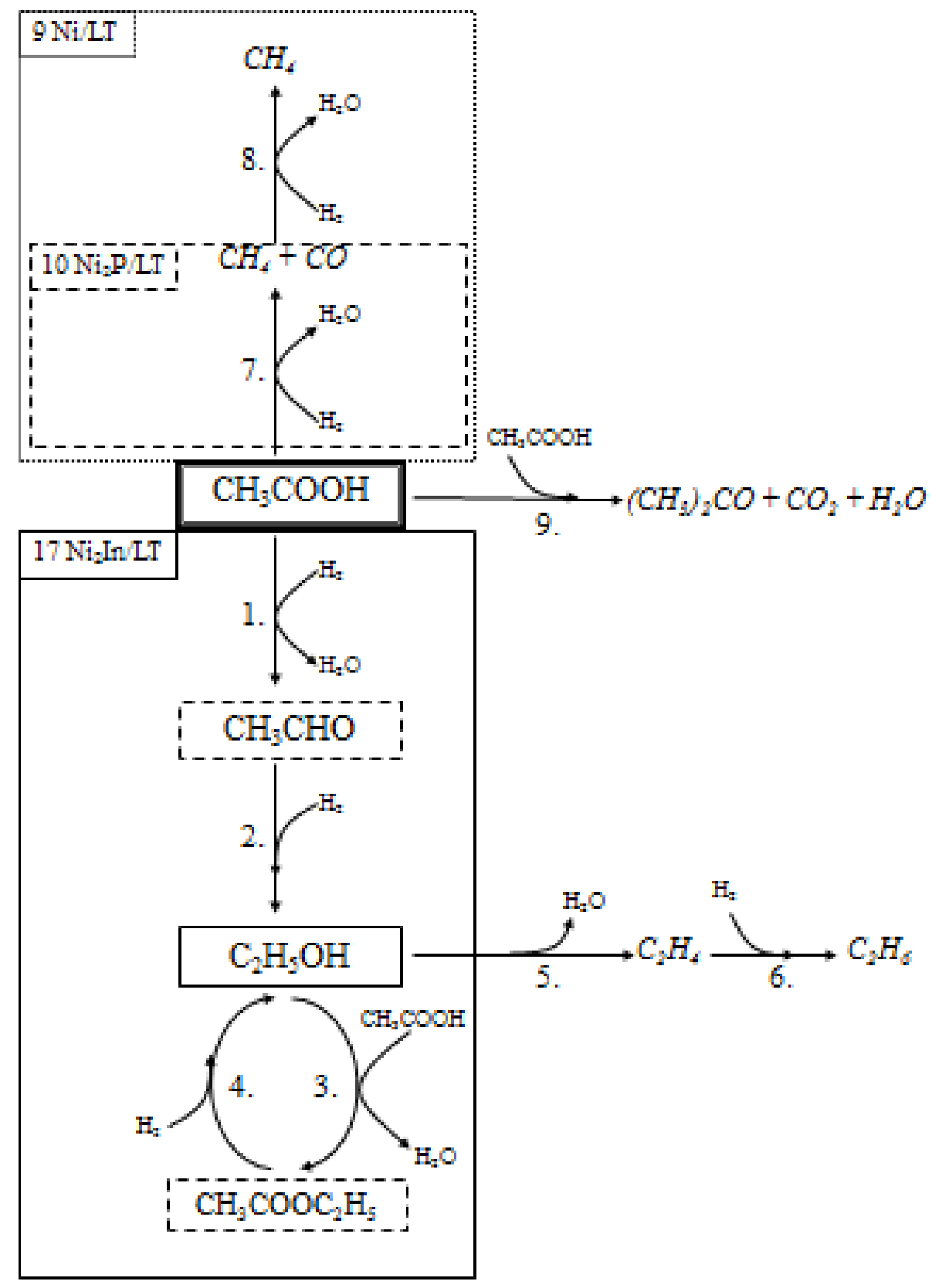


Figure 1.

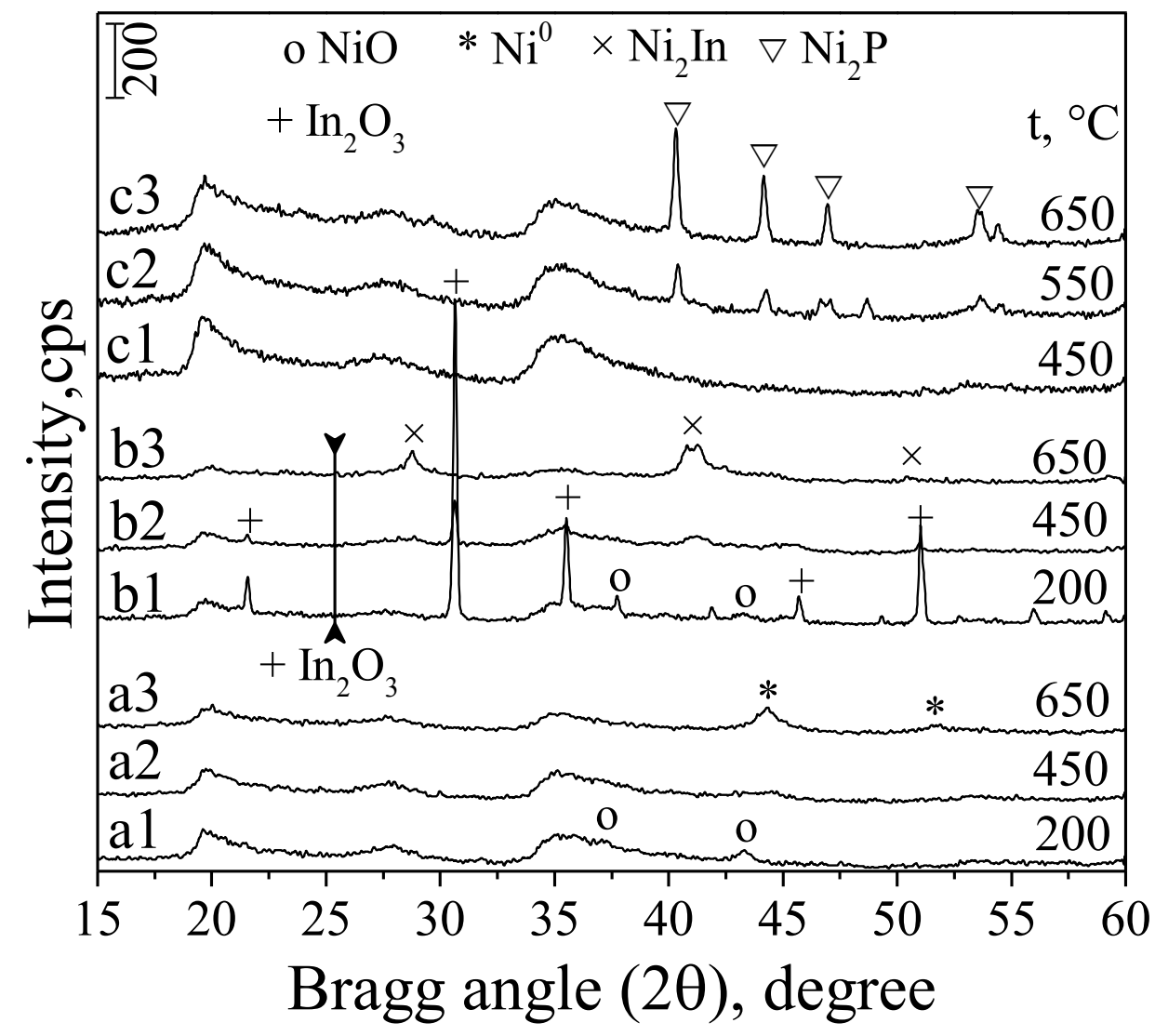

Figure 2. 


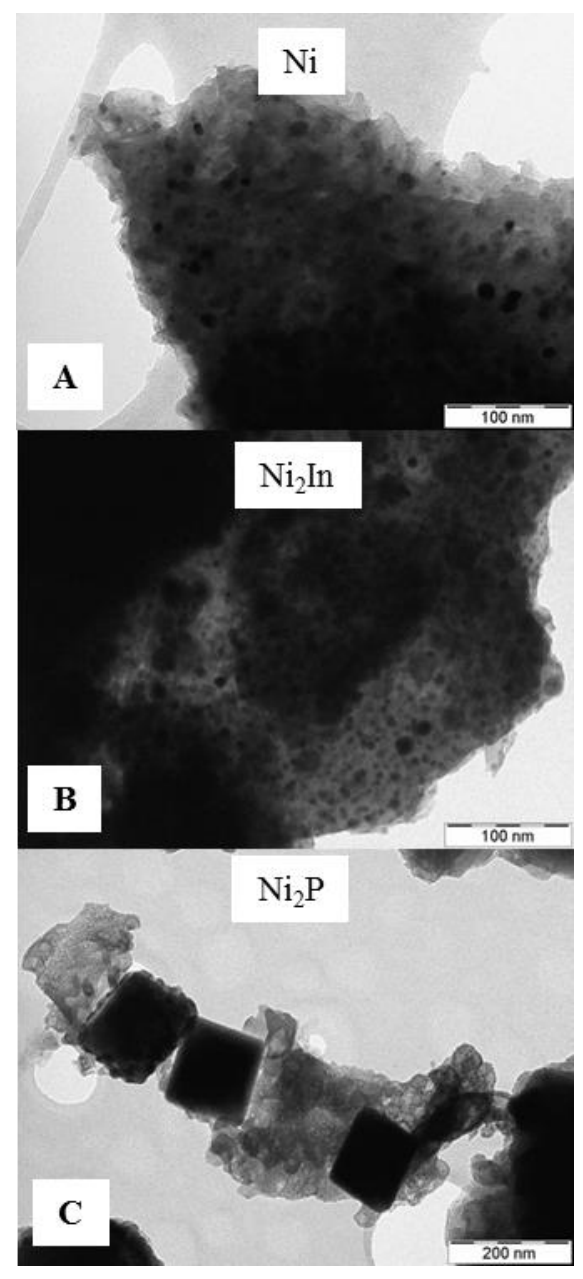

Figure 3. 

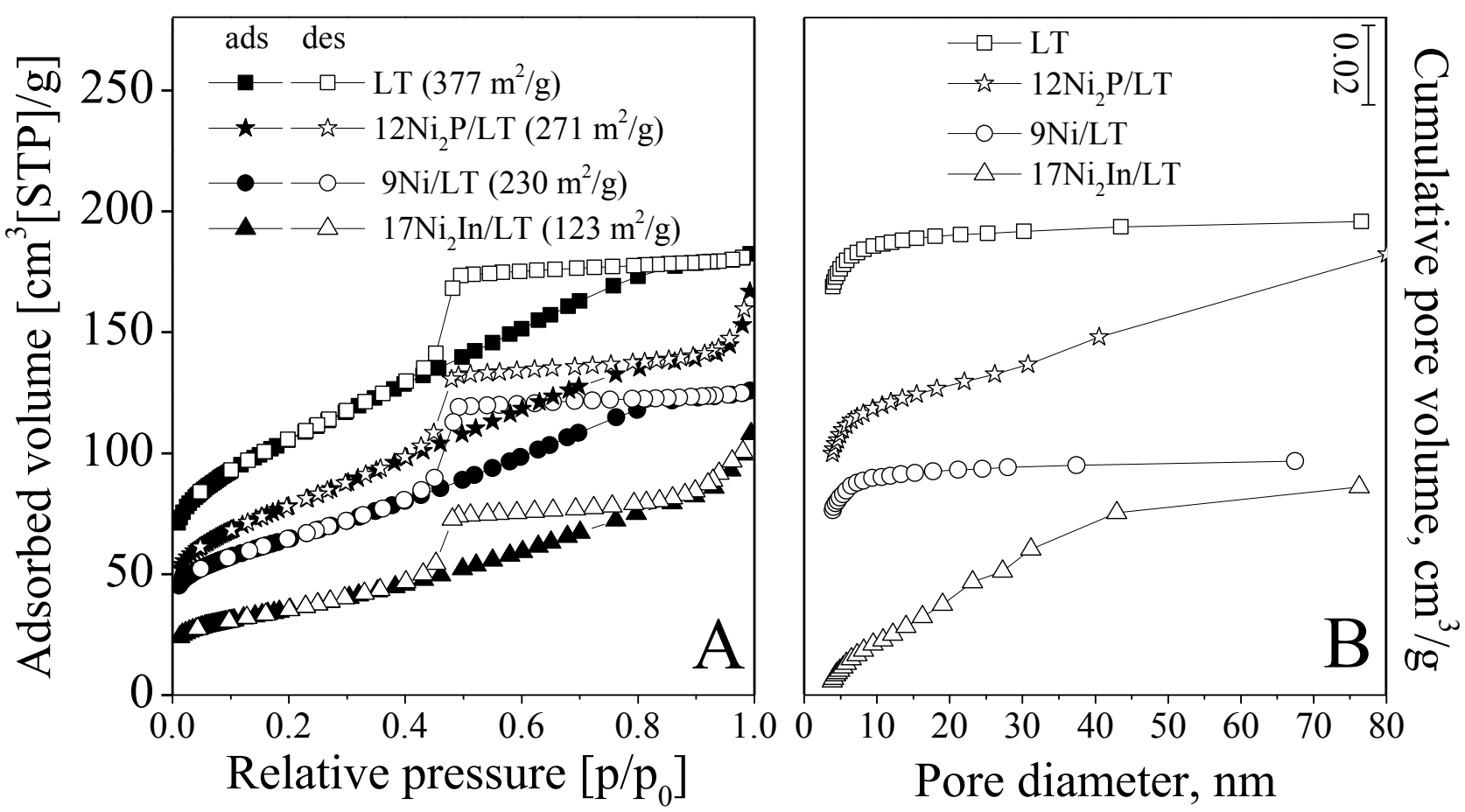

Figure 4.

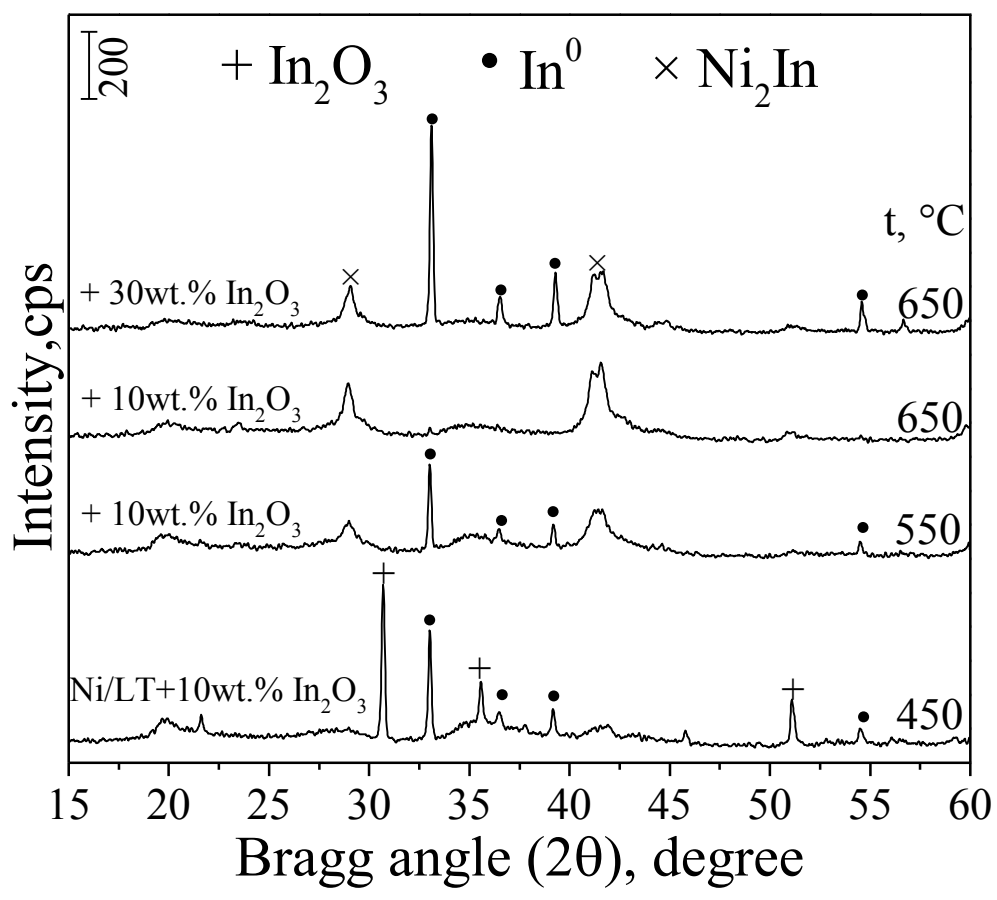

Figure 5. 


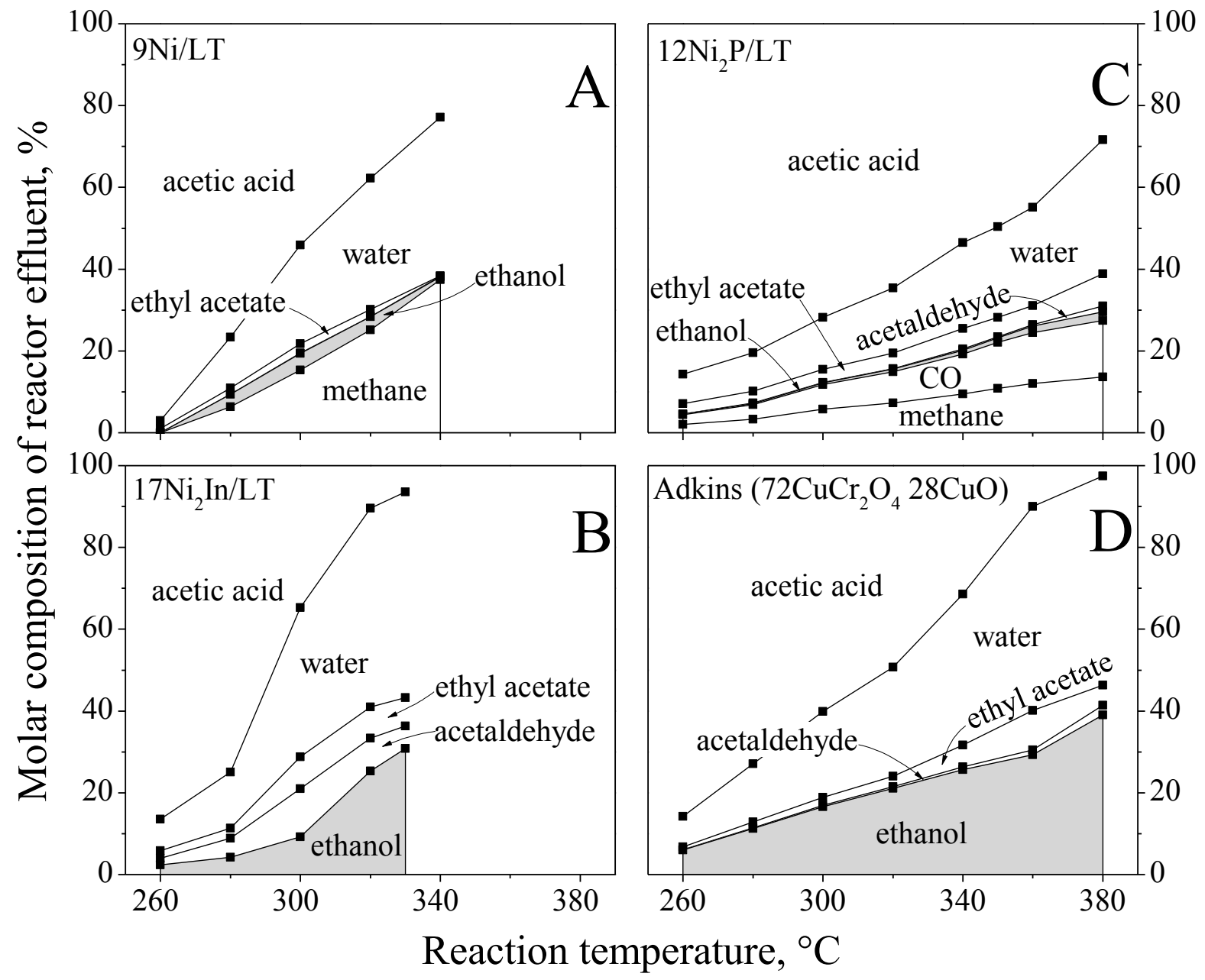

Figure 6. 


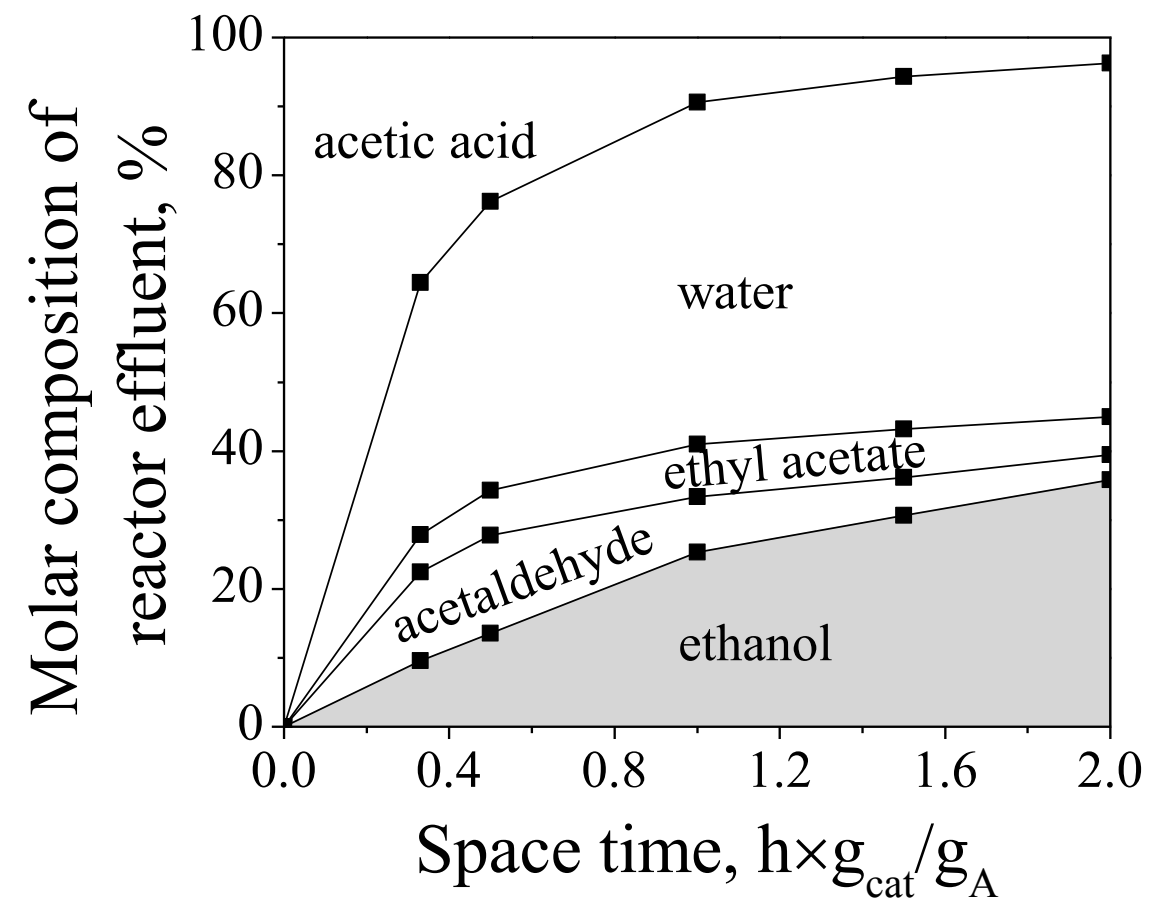

Figure 7.

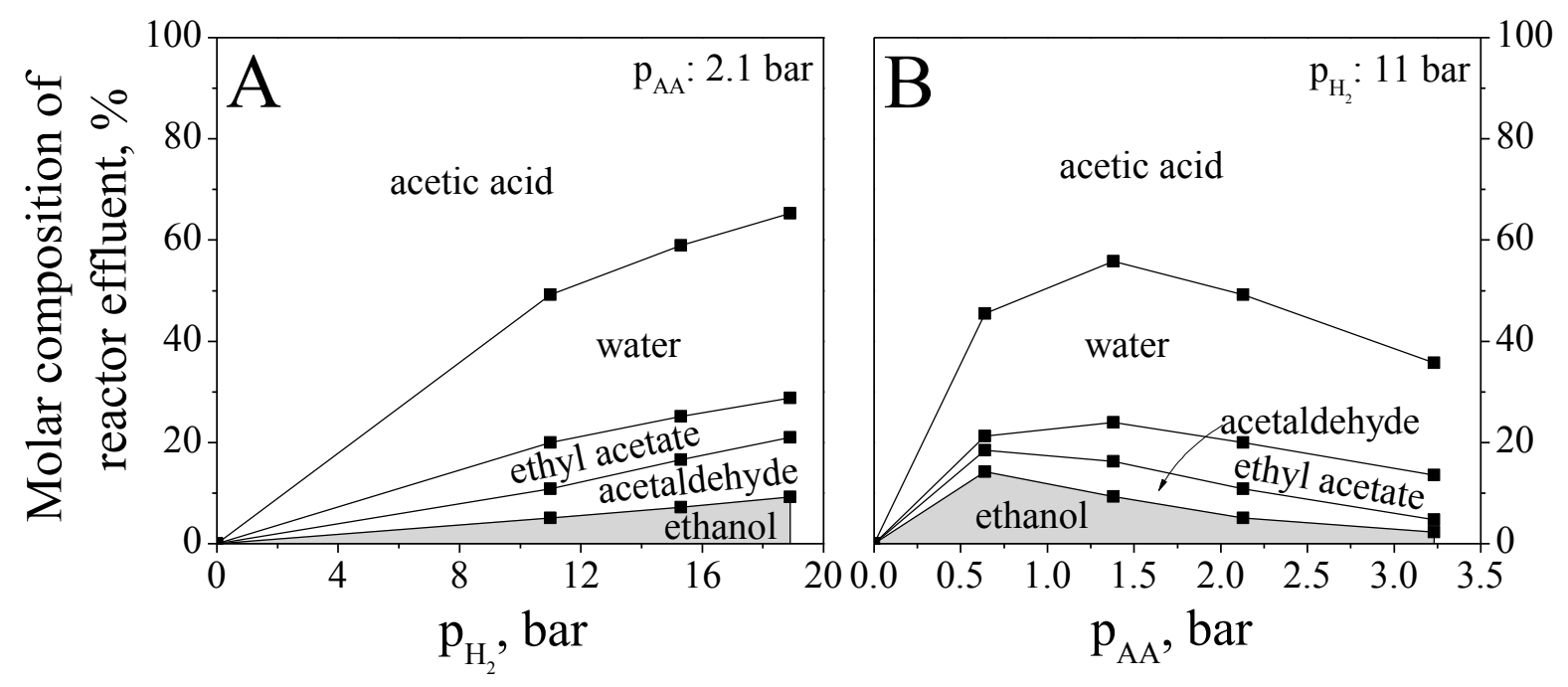

